\title{
Adhesion molecules and inflammatory injury
}

STEVEN M. ALBELDA, ${ }^{*, 1}$ C. WAYNE SMITH, ${ }^{\dagger}$ AND PETER A. WARD ${ }^{\ddagger}$

*Pulmonary and Critical Care Division, Department of Medicine, University of Pennsylvania Medical Center, Philadelphia, Pennsylvania 19104, USA; ${ }^{\dagger}$ Department of Pediatrics, Baylor College of Medicine, Houston, Texas 77030 USA; and ${ }^{ \pm}$Department of Pathology, University of Michigan Medical School, Ann Arbor, Michigan 48109, USA

\begin{abstract}
Neutrophil-endothelial cell interactions are mediated by interacting sets of cell adhesion molecules (CAMs) and chemoattractant/activator molecules to form an "adhesion cascade." The initial phase of inflammation, a transient slowing of neutrophils in postcapillary venules, is mediated by selectins. Subsequently, firm adhesion of neutrophils to the vessel wall occurs via interaction of the CD11/CD18 $\left(\beta_{2}\right)$ integrins to endothelial ligands such as intercellular adhesion molecule-1 (ICAM-1). This binding requires activation of CD11/CD18 by exposure of the neutrophil to a variety of activating/chemoattractant molecules, such as plateletactivating factor or interleukin-8. Finally, transmigration into tissues occurs, a process that requires both a chemotactic stimulus and engagement of plateletendothelial cell adhesion molecule-1 (PECAM-1). Several approaches have been used to probe the role of CAMs in vivo. These include the use of blocking antibodies, chimeric selectin-immunoglobulin proteins, sialyl Lewis ${ }^{x}$ oligosaccharides and peptides, along with the study of humans and animals with genetically determined adhesion deficiencies. These studies demonstrate that CAM blockade can effectively inhibit inflammation; however, there appear to be clear differences in the adhesion requirements for particular types of inflammation. By understanding the CAM/chemoattractant profiles involved in specific disease states, it may be possible to precisely and effectively target therapy to a wide variety of inflammatory diseases. - Albelda, S. M., Smith, C. W., Ward, P. A. Adhesion molecules and inflammatory injury. FASEB $J$. 8: 504-512; 1994.
\end{abstract}

Key Words: adhesion molecules - inflammation - endothelial cells - leukocytes - integrins - selectins - immunoglobulin superfamily $\cdot$ neutrophils $\cdot$ cell adhesion

THE RECRUITMENT OF LEUKOCYTES INTO AREAS OF inflammation begins with the binding of white blood cells to endothelium, followed by their transmigration into tissues. Although this observation has been documented for more than 150 years, only in the last decade, with the identification of specific cell adhesion and chemoattractant/activator molecules, have the molecular mechanisms underlying leukocyte adhesion been uncovered. Three families of cell adhesion molecules (CAMs) ${ }^{2}$ play a central role in leukocyteendothelial interactions: the selectins, the integrins, and the immunoglobulin superfamily (1) (see Table 1). In addition, factors that activate neutrophils or endothelial cells (Table 2), thereby resulting in CAM expression and/or chemotactic migratory responses, are also important. It is now recognized that these different types of CAMs and chemoattracts interact in a programmed, sequential manner to form what has been termed the leukocyte-endothelial cell adhesion cas- cade (2-5). The purpose of this review is to summarize recent information concerning the mechanisms by which leukocytes (specifically, neutrophils) enter regions of inflammation and how this information might be used to develop novel therapeutic approaches.

\section{THE ENDOTHELIAL CELL-LEUKOCYTE ADHESION CASCADE}

Most neutrophil emigration occurs in specialized regions of the vascular tree, i.e., in postcapillary venules, and can be divided into distinct phases (Fig. 1). When viewed with in vivo microscopy (reviewed in ref 6), the first event (Fig. $1 B$ ) is the slowing or margination of the circulating leukocytes within the venule where the white cells are only loosely tethered to the vessel wall and roll along the surface of the endothelium at velocities of less than $50 \mu \mathrm{m} / \mathrm{s}$. After a variable period of rolling, many neutrophils firmly adhere to the endothelial cell surface (Fig. 1C) and appear to become activated, changing from a spherical configuration to a flattened shape. Aggregates of neutrophils and some attached platelets are often seen. Adherent cells then migrate through the junctions of endothelial cells and move to a region between the endothelium and its basement membrane (Fig. 1D). After a brief pause in this location, the neutrophils finally migrate into the surrounding interstitial tissue. Each step of neutrophil emigration has been associated with specific CAMs and CAM activators or chemoattractants.

\section{Rolling}

The initial phase of the adhesion cascade, neutrophil rolling, is mediated by members of the selectin family. The selectins $(7,8)$ include a group of three related molecules. L-selectin (Lam-1, LECAM-1) is constitutively expressed on neutrophils and is shed from the cell surface on cell activation, assumed to occur immediately after rolling begins (9). Pselectin (GMP140 or PADGEM) is found on platelets and is stored in Weibel-Palade bodies where it is quickly (within minutes) moved to the cell surface after endothelial cell activation by stimuli such as histamine, thrombin, bradykinin, leukotriene $\mathrm{C}_{4}\left(\mathrm{LTC}_{4}\right)$, or free radicals. E-selectin (ELAM-1)

'To whom correspondence should be addressed, at: 809 Maloney Bldg./H. U. P., 3600 Spruce St., Philadelphia, PA 19104, USA.

${ }^{2} \mathrm{CAM}$, cell adhesion molecule; PECAM-1, platelet-endothelial cell adhesion molecule; Ig, immunoglobulin; TNF $\alpha$, tumor necrosis factor- $\alpha$; IL-1, interleukin 1; LFA-1, lymphocyte function antigen-1; PAF, platelet activating factor; IL-8, interleukin 8; ICAM, intercellular adhesion molecule; VCAM-1, vascular cell adhesion molecule-1; LTB4, leukotriene B4; LAD, leukocyte adhesion deficiency; LPS, lipopolysaccharide. 


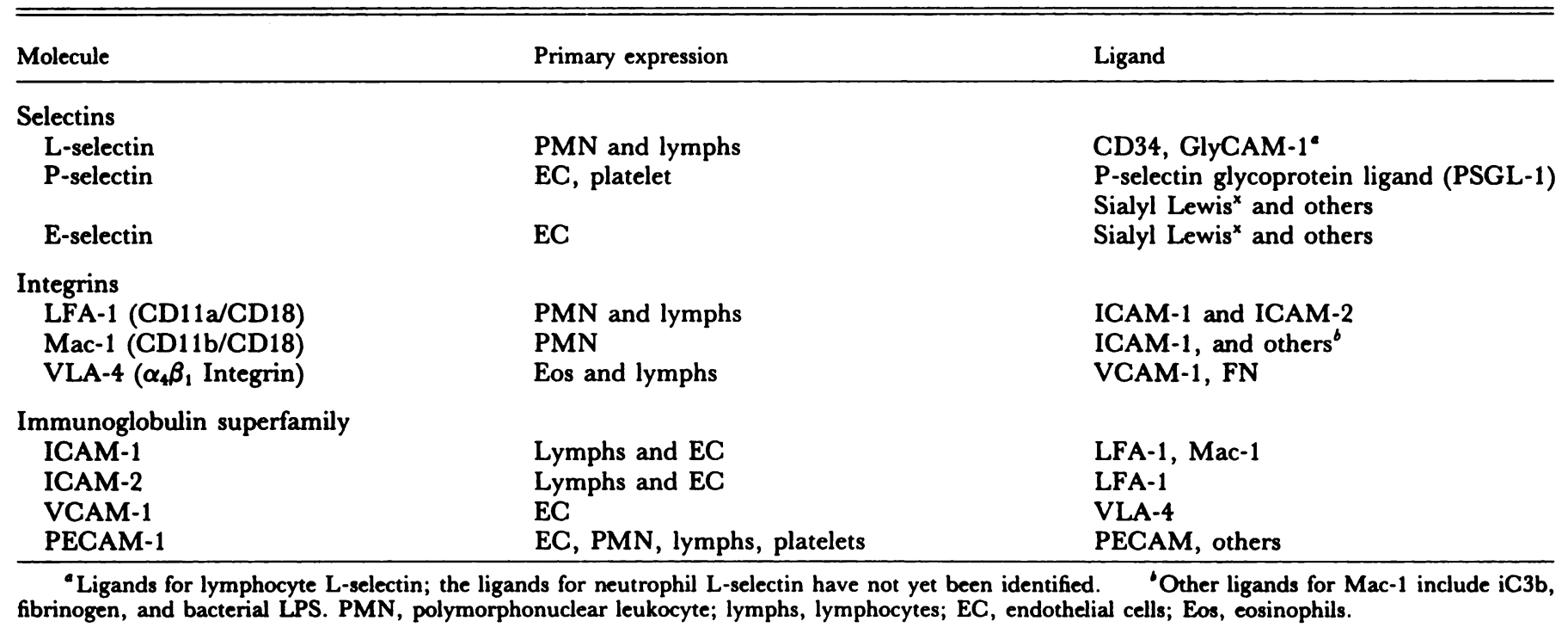

is expressed solely on endothelial cells where it is synthesized rapidly after cell stimulation by cytokines (TNF $\alpha, \mathrm{IL}-1)$ or endotoxin and then translocated to the luminal surface of the venular endothelium.

Each selectin shares a common molecular structure, most notably an $\mathrm{NH}_{2}$-terminal lectin-like domain, that imparts the ability of each selectin to bind to specific carbohydrate ligands. To date, three structures have been identified that appear to have binding affinity for selectins: 1) oligosaccharides related to sialyl Lewis ${ }^{\mathbf{x}}$ and sialyl Lewis ${ }^{\mathbf{a}}$; 2) phosphorylated mono- and polysaccharides; and 3) sulfated polysaccharides and lipids (7). It is still unclear which molecules (in the form of glycoconjugates) present these carbohydrate derivatives to the selectins as counter-receptors. Although ligands for lymphocyte $\mathrm{L}$-selectin on high endothelial venules have been identified and cloned (10), a similar ligand for neutrophil L-selectin on activated endothelium has yet to be identified. One function of L-selectin may be to present molecules of sialyl-Lewis ${ }^{x}$ to E-selectin and P-selectin and thus to serve as one of the counter receptors for selectins on endothelial cells and platelets $(11,12)$. Recently, Sato et al. (13) used expression cloning to identify a mucin-like transmembrane glycoprotein that functions as a ligand for $\mathrm{P}$. selectin on myeloid cells when appropriately glycosylated (termed P-selectin glycoprotein ligand or PSGL-1).

\section{Activation and firm adhesion}

Although rolling appears to be a prerequisite for eventual firm adherence to blood vessels under conditions of flow (14), selectin-dependent adhesion of leukocytes does not lead to firm adhesion and transmigration unless another set of adhesion molecules is engaged. For neutrophils, firm adhesion requires activation of the $\beta_{2}(C D 18)$ integrin family, resulting

TABLE 2. Neutrophil and endothelial cell activating factors

\begin{tabular}{|c|c|c|}
\hline \multirow[b]{2}{*}{ Activating agent } & \multicolumn{2}{|c|}{ Targets } \\
\hline & Neutrophils & Endothelial cells \\
\hline & $\begin{array}{l}\text { Tumor necrosis factor } \alpha \text { (TNF } \alpha) \\
\text { Interleukin-1 (IL-1) }\end{array}$ & $\begin{array}{l}\text { TNF } \alpha \\
\text { IL-1 } \\
\text { Interleukin-4 } \\
\text { Interferon- } \gamma\end{array}$ \\
\hline Lipids & $\begin{array}{l}\text { Leukotriene } \mathrm{B}_{4}\left(\mathrm{LTB}_{4}\right) \\
\text { Platelet-activating factor (PAF) } \\
\text { Bacterial endotoxin }\end{array}$ & \\
\hline
\end{tabular}


A

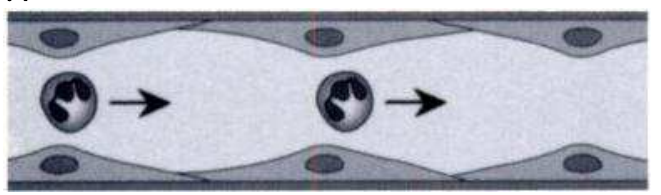

Baseline

B

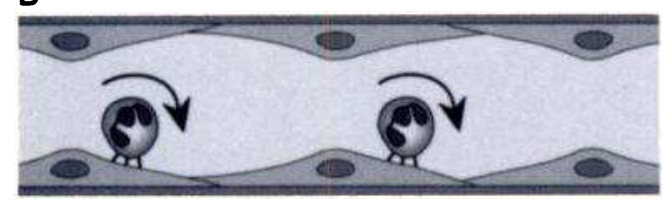

Rolling

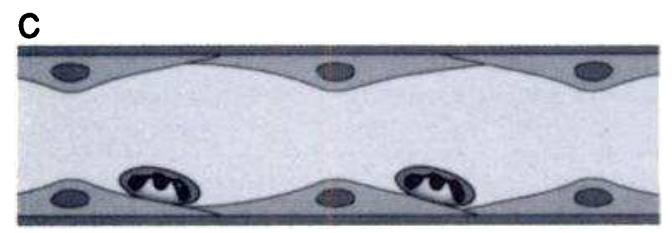

Activation

and

firm adhesion

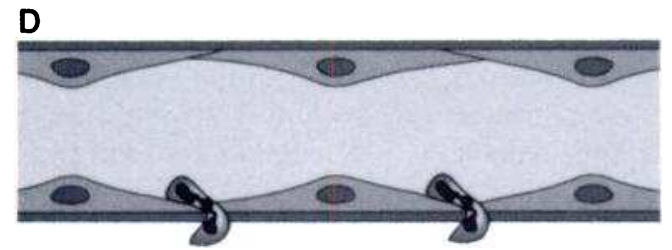

Transmigration

Figure 1. The endothelial cell-leukocyte adhesion cascade. Under baseline conditions $(A)$, neutrophils are nonadherent to the vessel wall. The first event in white cell emigration is the slowing or rolling of the circulating leukocytes within the venule mediated by selectins $(B)$. After a variable period of rolling, an activation event occurs resulting in neutrophils firmly adhering to the endothelial cell surface $(C)$ and changing from a spherical configuration to a flattened shape. This process requires interaction of activated CD18 integrins on neutrophils with immunoglobulin superfamily members (i.e., ICAM-1) on the endothelium. Adherent cells then transmigrate through the junctions of endothelial cells $(D)$, an event that requires a chemotactic gradient and involvement of the adhesion molecule, PECAM-1. After a brief pause in this location, the neutrophil finally migrates into the surrounding interstitial tissue.

in binding to one of the intercellular adhesion molecules on the surfaces of endothelial cells.

The CD11/CD18 integrins, specifically CD11a/CD18 (LFA-1) and CD11b/CD18 (Mac-1), were among the first cell adhesion molecules to be identified and characterized (14, 15). As typical members of the integrin family, these molecules are heterodimers composed of unique $\alpha$ subunits noncovalently bound to a common $\beta$ subunit $\left(\beta_{2}\right)$ (1). Although both CD11a and CD11b interact with the immunoglobulin superfamily member, ICAM-1, CD11b is capable of binding a wide range of ligands, including fibrinogen, denatured albumin, and complement fragments (iC3b) (16), as well as unidentified ligands on endothelial cells (17).

An important characteristic of the neutrophil integrins is that under baseline conditions they exist in a relatively inactive conformation, rendering the leukocyte nonadhesive. One of the key events of the adhesion cascade is the activation (sometimes accompanied by the addition of protein on the cell surface) and deactivation of these integrins at the proper times and places. Evidence for a conformational change associated with high avidity is found in the binding of some monoclonal antibodies that appear to recognize epi- topes found only in the activated or bound state of the integrins $(18,19)$.

One important pathway by which integrin activation appears to occur is that neutrophils interact with stimulatory molecules that are bound to the surface of the endothelium. This idea is attractive for several reasons. First, it explains how chemoattractants could act quickly enough to target leukocyte migration before being swept downstream. Second, most of the chemoattractant molecules, in addition to activating integrins, also cause shedding of L-selectin and stimulate neutrophil locomotion. Kishimoto et al. (9) proposed that shedding of L-selectin may facilitate cell migration by releasing a potentially tethering adhesive mechanism as neutrophils shift to $\beta_{2}$ integrin-dependent migration. Location and timing of this stimulation may be critical as, in fact, many chemoattractant molecules have well-documented leukocyte adhesion inhibitory activity when presented to neutrophils in soluble phase (20).

Good evidence to support the importance of surface activation in white cell emigration has been presented for two inflammatory mediators: platelet-activating factor (PAF) and interleukin-8 (IL-8). PAF is synthesized by endothelial cells within minutes after stimulation by thrombin, histamine, LTC 4 , or other agonists, and is expressed on the cell surface where it activates neutrophils and up-regulates CD11b by binding to a specific cell-surface receptor (21). Many of the same factors that stimulate PAF expression also cause rapid translocation of P-selectin to the surface of the endothelium (see above). Thus, for at least one set of stimuli both a specific tethering molecule ( $\mathrm{P}$-selectin) and a specific activator molecule (PAF) are produced. A similar situation may exist for the neutrophil chemoattractant/activator IL-8. IL-8 appears to bind to the luminal surface of activated endothelial cells where it is able to activate neutrophils (22). Because cytokines, such as TNF $\alpha$, and other factors (such as endotoxin) cause the synthesis of both IL-8 and E-selectin from endothelial cells (23), it is likely that these mediators may augment neutrophil transmigration by stimulating expression of both the tethering molecule and the activating factor (24).

Important ligands for the CD11/CD18 integrins are ICAM-1, and possibly ICAM-2 (reviewed in ref 21). These molecules, members of the immunoglobulin superfamily, are present constitutively on endothelial cells both in vitro and in vivo. CD11a and CD11b bind to ICAM-1 in different regions of the molecule. Only CD11a has been shown to be capable of binding to ICAM-2. Constitutive expression of endothelial ICAM-2 is relatively stable, whereas ICAM-1 expression can be augmented by a variety of inflammatory mediators including TNF, IL-1, $\gamma$-interferon, and endotoxin. The increase in expression is dependent on protein synthesis and peaks about $8 \mathrm{~h}$ after stimulation in both in vitro (2) and in vivo models (25). Monoclonal antibody blocking experiments suggest that ligands in addition to ICAM-1 may be important in neutrophil-endothelial interactions $(5,26)$. Even with the relatively high levels of ICAM-1 on resting endothelium, it appears that the additional expression induced by cytokines is important in neutrophil-endothelial interactions.

\section{Transmigration}

Transendothelial cell migration does not necessarily accompany leukocyte adherence to the endothelium. Although chemotactic factors, such as $\mathrm{LTB}_{4}, \mathrm{C} 5 \mathrm{a}$, and f-Met-Leu-Phe, can augment leukocyte adhesion to endothelium (reviewed in ref 27), transmigration across an endothelial monolayer requires a chemotactic gradient (28). Spontaneous trans- 
migration of neutrophils through TNF $\alpha$ - or IL-1-stimulated endothelial monolayers has been observed $(29,30)$; however, it is likely that these cytokines also cause expression of potent chemotactic stimuli such as IL-8 (24), which for the reasons cited above, affect both adherence and transmigration of neutrophils.

Recent studies have implicated another adhesion molecule, platelet-endothelial cell adhesion molecule-1 (PECAM-1), in transmigration. PECAM-1, a member of the immunoglobulin superfamily, is expressed at relatively low levels on the surface of leukocytes and platelets but at higher levels $\left(>10^{6}\right.$ molecules per cell) on endothelium (31). Its localization at the junctions between endothelial cells has suggested a role in transendothelial cell migration. Using an in vitro model, Muller et al. (30) demonstrated that antibodies against PECAM-1 significantly blocked leukocyte transmigration through TNF $\alpha$-activated endothelial cell monolayers but did not affect the adhesion of neutrophils. This effect has recently been confirmed in animal models of neutrophil transmigration (32). The mechanisms by which PECAM-1 may regulate transendothelial migration are not yet known; however, the possibilities include direct binding of PECAM-1 to the leukocyte (perhaps serving as a molecular guide as it passes through the junction), or regulation of adhesion molecules on the surface of the leukocyte (i.e., $\beta_{2}$ integrins), thus facilitating transmigration (30). Available data indicate that cross-linking of PECAM-1 on the surface of leukocytes by antibodies can up-regulate integrin-mediated binding (33).

Another process that may play an important role in transendothelial migration is the ability of the endothelial cell monolayer to regulate an opening of its junctions, allowing neutrophil transmigration. Recent work by Huang et al. (34) suggests that transmigrating neutrophils (in response to a chemotactic stimulus) exert an active influence on the endothelial cell monolayer, resulting in increased intracellular endothelial calcium levels and opening of intercellular junctions.

\section{NONCASCADE DEPENDENT LEUKOCYTE EMIGRATION}

As a general rule, neutrophil transmigration appears to be preceded by endothelial activation (defined by up-regulation of adhesion molecules). However, this cascade may not be operative during all types of inflammatory reactions. Several chemoattractant/activators are able to directly up-regulate neutrophil CD11b/CD18 activity and allow adhesion of the leukocytes to resting, unactivated endothelial cells (perhaps by binding to constitutively expressed ICAM-1) without apparent involvement of selectins. This process is also probably operative in vivo (4). It thus seems likely that in vascular beds where blood flow is diminished (by geometric constraints or by vascular occlusion/vasoconstriction), activation of the CD18 integrins, along with the presence of a chemotactic gradient, may be sufficient for neutrophil transmigration, without additional activation of endothelium. This mechanism may be operative in clinical situations, such as sepsis, where intravascular activation of neutrophils leads to neutrophil sequestration in the lung and other organs.

Another process that may be an accessory means of localizing additional neutrophils at the early stages of inflammatory reaction is neutrophil aggregation. This represents both homotypic aggregation between neutrophils, a phenomenon that has been shown in vitro to be primarily a CD11b-dependent event (35), and heterotypic aggregation between neutrophils and platelets, an event primarily dependent on P-selectin, at least in vitro (36).
INFLAMMATION AND THE ADHESION CASCADE

Because of the complexity and diversity of the inflammatory response, it has been increasingly important to evaluate the role of cell adhesion molecules in animal models of specific inflammatory events. Probing the role of adhesion molecules involved in in vivo inflammatory responses has taken several different approaches. One strategy has been to infuse soluble forms of CAMs to compete with naturally occurring in vivo selectin molecules and inhibit neutrophil accumulation (37, 38). These studies have, for the most part, used chimeric selectin-Ig proteins (which contain the extracellular portions of selectins fused to the $\mathrm{CH} 2$ and $\mathrm{CH} 3$ domains of the IgG heavy chain), as these hybrids have a longer half-life than soluble forms of selectins when infused intravenously. The infusion of an L-selectin chimera significantly inhibited the number of neutrophils migrating to the peritoneum in response to an inflammatory infiltrate (37). In rat models, Land $\mathrm{P}$-selectin chimeras blocked complement-mediated lung injury, whereas L- and E-selectin chimeras inhibited immune complex-induced lung damage (38). A related strategy, shown to be useful in the case of either E-selectin or P-selectin-dependent inflammatory reactions, involves the infusion of sialyl Lewis ${ }^{x}$ oligosaccharides (the penta and tetra versions) that appear to compete with selectindependent binding interactions (39). It may also be possible to design peptides that simulate the binding site of an adhesion molecule. To date, this has been chiefly used to interfere with P-selectin (40) or CD11b-dependent reactions in vitro (41). The applicability of these peptides in vivo remains to be determined.

Another approach that has yielded a great deal of information about the in vivo role of adhesion molecules has been the study of animals (or humans) in which there is a naturally occurring or artificially induced CAM defect. Some of the earliest clues suggesting the clinical importance of cell adhesion molecules came from the study of congenitally acquired syndromes featuring impaired host defenses against bacterial pathogens. Leukocyte adhesion deficiency (LAD) type I (reviewed in ref 15 ) is characterized by a profound defect in phagocyte emigration, chronic neutrophilia, and recurrent infections without formation of pus, and is due to a deficiency of members of the CD11/CD18 family of adhesion molecules on neutrophils as a result of a number of different mutations. Neutrophils isolated from LAD-type I patients show normal rolling behavior, but are incapable of sticking to endothelial monolayers or emigrating in response to chemotactic stimuli. The recently described LAD-type II (42) is characterized by a very similar clinical scenario; however, molecular analysis has revealed that this syndrome is due to a congenital defect of endogenous fucose metabolism. This results in an inability to synthesize fucosylated carbohydrate molecules, such as sialyl Lewis ${ }^{x}$, and a crippled selectin system. Consistent with predictions, neutrophils isolated from LAD type II patients are able to adhere normally to activated endothelial monolayers under static conditions but show marked defects in rolling and adherence under shear force (43).

More recently, it has been possible to begin to explore the role of leukocyte-endothelial cell molecules in inflammation by studying mice engineered using homologous recombination techniques to lack specific CAMs. Wilson et al. (44) have developed mice that express only $2-16 \%$ of the normal levels of CD18 expression on granulocytes. These animals show an impaired inflammatory response to a chemical peritonitis and delayed rejection of cardiac grafts. "Knock- 
outs" of two of the immunoglobulin superfamily cell adhesion molecules have also recently been achieved. Mice deficient in VCAM-1 expression are not viable and die in utero due to cardiac and other developmental abnormalities (45). In contrast, mice deficient in ICAM-1 (46) develop normally, are fertile, and appear normal except for a moderate granulocytosis. However, these ICAM-1-deficient animals exhibit impaired neutrophil emigration in response to chemical peritonitis and decreased contact hypersensitivity to 2,4, dinitrobenzene. In addition, leukocytes from these mice provide negligible stimulation for the mixed lymphocyte reactions. Mice lacking P-selectin (47) develop normally; however, they exhibit a striking leukocytosis, diminished rolling of leukocytes in mesenteric vessels, and delayed recruitment of neutrophils to the peritoneal cavity after experimentally induced peritonitis. E-selectin-deficient mice (45) have a similar phenotype with regard to delay in neutrophil recruitment into experimentally induced peritonitis, but do not have leukocytosis. Administration of anti-P-selectin antibody to the E-selectin knockout mice completely blocks neutrophil recruitment, suggesting that in this model some redundancy of function may exist between the two endothelial cell selectins. The degree of immune deficiency in most of the knockout animals is not as severe as in humans and bovines with the severe form of LAD I deficiency who naturally acquire acute life-threatening bacterial infections at an early age. Early deletion of a specific CAM may allow alternative pathways to develop. A significant problem in evaluation of the gene knockout animals maintained in barrier facilities is the need to apply highly quantitative and reliable techniques for the in vivo measurement of possible changes in expression of the inflammatory response.

Much of our knowledge about the role of CAMs in inflammation has come from the use of blocking antibodies. This approach has not been entirely straightforward, however, because of the inability of many well-characterized blocking antibodies to cross-react in animals species, the tendency of some antibodies (i.e., anti-L-selectin) to induce neutropenia, and interactions by the Fc portion of some antibodies necessitating the use of $F\left(a b^{\prime}\right)_{2}$ fragments (48). Nevertheless, these difficulties have been solved in different ways, including careful screening of known bioactive human monoclonal antibodies against a variety of animal species and looking for cross-reactivity (e.g., ref 48), the generation of rodentspecific bioactive antibodies, and by transplantion of human tissues into immunodeficient mice (25).

\section{Selectins}

The role of L-selectin in neutrophil transmigration in vivo was first demonstrated by Jutila et al. (49), who showed that an antibody (MEL-14) against the murine form of L-selectin could suppress neutrophil accumulation within the inflamed peritoneum of a mouse by about $70 \%$. Ley et al. (50), using intravital microscopy, directly demonstrated a decrease in the number of neutrophils undergoing rolling within rat mesenteric venules after administration of a polyclonal antiL-selectin antibody.

Despite a great deal of in vitro work indicating that $\mathrm{E}$ selectin is important in neutrophil-endothelial cell adhesion (reviewed in ref 7), the lack of cross-reacting antibodies has limited in vivo experiments. There are only a few reports demonstrating blockade of white cell emigration by inhibition of E-selectin function in an intact animal. Mulligan et al. (48) were able to block neutrophil migration into glycogen-induced peritoneal exudates and immune complexinduced skin and lung inflammation with a murine anti- human E-selectin antibody discovered to cross-react with rat E-selectin. Gundel et al. (51) were able to inhibit the influx of neutrophils associated with the late-phase airway inflammation in a primate model. Antibodies against human Eselectin have recently been used to block white cell emigration in TNF $\alpha$-activated human skin transplanted onto SCID mice (52).

Similar problems with appropriate cross-reacting bioactive antibodies have also hindered the understanding of the physiologic role of P-selectin. Recently, however, inflammatory reactions that appear to depend heavily on P-selectin interactions have been identified. These include pulmonary vascular injury secondary to intravenous complement activation (53) and ischemia/reperfusion injury $(54,55)$.

\section{CD11/CD18}

The development of monoclonal antibodies with the ability to block CD11a, CD11b, and/or CD18 function in animals without causing neutropenia has allowed many experiments to be performed examining the role of CD18 in inflammation (the reader is referred to several excellent reviews $[5,6]$ that discuss this topic in detail). Of all the adhesion molecules studied to date, CD18 seems to have the most wide-ranging and powerful effects. Blockade of the CD11/CD18 complex has been shown to inhibit neutrophil influx in almost every system tested to date, including skin, peritoneum, synovium, lung, kidney, and heart. Accordingly, intravenous application of anti-CD11/CD18 antibodies have been shown to reduce inflammation and injury in models of allograft rejection, endotoxic and hemorrhage shock, hypersensitivity reactions, bacterial meningitis, aspiration lung injury, pneumonia, and ischemia reperfusion. There are a few examples where both CD18-dependent and CD18-independent pathways of neutrophil emigration have been identified, including certain types of lung inflammation (56) and the late movement of neutrophils into inflammed peritoneum (57).

\section{ICAM-1}

As one of the primary ligands for the CD18 integrins, it would be expected that blockade of ICAM-1 would inhibit the inflammatory response. Some studies (again, see ref 6 for review) have shown effects of ICAM-1 antibodies in various models of inflammation such as transplant rejection, delayed hypersensitivity, asthma, ischemia/reperfusion, and immune complex injury.

\section{CELL ADHESION MOLECULE INVOLVEMENT DEPENDS ON THE ORGAN AND THE NATURE OF THE INFLAMMATORY STIMULUS: LESSONS FROM INFLAMMATORY ANIMAL MODELS}

One of the most important lessons that has emerged from animal studies of CAMs is that there are distinct differences in the adhesion requirements for particular types of inflammation. This point is clearly illustrated by comparing a series of studies by Mulligan et al. $(38,39,48,53,58-62)$ conducted in well-characterized rat models of inflammation. In these experiments, summarized in Table 3, the effects of bioactive antiadhesion molecule antibodies or selectin-Ig chimeras on the intensity of tissue injury in four different models of inflammation are compared. Whereas anti-CD18 antibodies are effective in blocking all forms of neutrophildependent inflammation, there seem to be differential contributions of CD11a vs. CD11b. Another interesting difference is that the selectin requirements of various inflamma- 
Reduction (\%) in Inflammatory Injury by antibody or selectin-chimera blockade

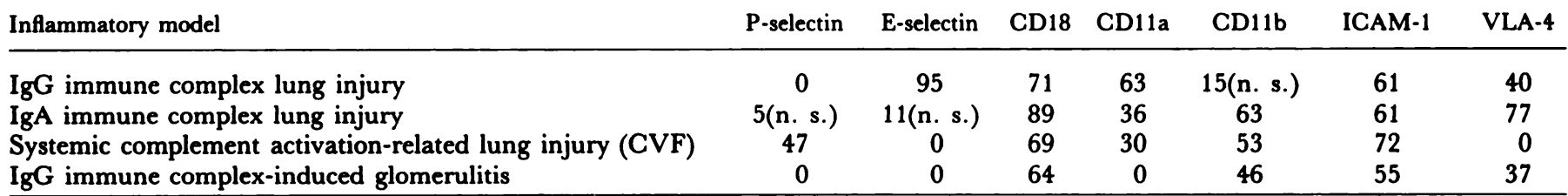

"As measured by vascular permeability or hemorrhage in the case of lung injury and proteinuria $(24 \mathrm{~h})$ in the case of glomerulonephritis. Except as designated by $n$. s. (not significant), all values were statistically significant $(P<0.05)$. See refs $38,39,48,53,58-62$ for details.

tory models, even within the same organ system, are quite different. For example, E-selectin expression is up-regulated in the pulmonary vasculature after intratracheal instillation of lipopolysaccharide (LPS), IL-1, TNF $\alpha$, or deposition of IgG immune complexes (Fig. 2). Accordingly, antibodies to E-selectin blocked neutrophil influx and tissue injury in IgG immune complex-mediated lung disease (48). However, antiE-selectin antibodies had no effect on $\operatorname{IgA}$-mediated immune complex lung disease, a model where tissue macrophages seem to play a dominant role (59). It is hoped that as more models of injury are carefully studied, a set of rules will emerge that will define which combination of cell adhesion molecules, cytokines, and chemoattractants is involved in specific disease states.

\section{THERAPEUTIC APPROACHES}

Interruption of the leukocyte-endothelial cell cascade has become a major focus of anti-inflammatory research. Several approaches are being developed. The blockade of CAM function by use of specific blocking monoclonal antibodies is one strategy. For example, anti-LFA-1 monoclonal antibodies have been used to prevent graft failure in patients receiving HLA-mismatched bone marrow transplants (63). Clinical trials are currently under way using anti-ICAM-1 antibodies to inhibit kidney allograft rejection (64). Obviously, the use of monoclonal antibodies in the treatment of human diseases will be limited by the generation of antimurine antibodies by the recipient. However, the use of monoclonal antibodies may be useful for problems that would benefit from shortterm therapies, such as acute transplant rejection, prevention of ischemia reperfusion injury, or in well-defined episodes of sepsis or tissue injury. Humanization of murine antibodies may provide some advantage by limiting the production of antimurine antibodies.

Because of problems such as immunogenicity, the potential for causing immune complex disease, and requirements for intravenous administration, a number of alternative ways to inhibit cell adhesion molecules, are being explored. Soluble forms of adhesion molecules represent one such approach. Neutrophil influx has been inhibited in vitro with soluble $P$-selectin (65) and in murine and rat models using soluble selectin-IgG chimeras $(37,38)$. Unfortunately, the bioactivity of other soluble recombinant adhesion receptors, E-selectin for example (66), seems to be quite low. The difficulty in preparing large quantities of these receptors and the requirement for intravenous delivery further limit their potential utility. As mentioned above, the creation of peptide mimetics of active binding regions of CAMs is also being explored. Short peptides based on sequences of ICAM-1 (41, 67), P-selectin (40), and PECAM-1 (68) have been shown to block certain in vitro adhesion events and could potentially be useful in animal models.

Of more practical use would be small molecular weight compounds with the potential for oral administration. The discovery that selectin-mediated adhesion is dependent on carbohydrate binding has generated a great deal of interest in creating bioactive and biostable analogs of sialyl-Lewis ${ }^{x}$ or related sugars (see ref. 69 for example). Recent work in rat models of inflammation (39) have demonstrated the therapeutic feasibility of this strategy. Another approach that holds promise is the use of antisense oligonucleotides directed at cell adhesion molecules. Bennett et al. (70) have been able to design oligonucleotides that selectively inhibit the expression of ICAM-1, VCAM-1, and E-selectin in human endothelial cells, as well as block leukocyte adhesion to TNF-stimulated endothelium in vitro. Preliminary studies indicate that an antisense oligonucleotide directed toward murine ICAM-1 exhibits anti-inflammatory activity in several mouse models of inflammation (71).

Finally, several agents appear to inhibit integrin-mediated white cell adhesion by unknown mechanisms. A partial listing of such compounds would include $\mathrm{PGE}_{1}$ (72), lipoxin $\mathrm{A}$ (73), nitric oxide (74), adenosine (75), and dapsone (76). One of the most promising new families of molecules are the leumedins, a new class of anti-inflammatory compounds whose only known mechanisms of action to date is blockade of integrin $\beta_{2}$ function (77). One of these compounds has been effective in increasing survival in endotoxin-treated mice (78). The clinical applications of these new therapeutics, along with agents designed to inhibit chemoattractant molecules and cytokines (79), will doubtlessly be tested in the near future.

\section{CONCLUSIONS}

Our understanding of the mechanisms of leukocyte emigration into areas of inflammation has increased dramatically in the past decade. New adhesion molecules have been identified. The physiological and pathophysiological roles played by these molecules are rapidly being determined, along with the realization that certain subsets of adhesion molecules may be important in specific forms of inflammation. The complex relationships between adhesion molecules, cytokines, and chemoattractants are also of active interest.

This knowledge has generated expectations that strategies designed to inhibit cell adhesion will lead to novel and clinically useful forms of anti-inflammatory treatments. This goal is likely to be realized first in acute, self-limited disorders amenable to treatment by intravenous infusion, such as ischemia/reperfusion injury or early organ transplant rejection. By understanding the precise CAM/chemoattractant 

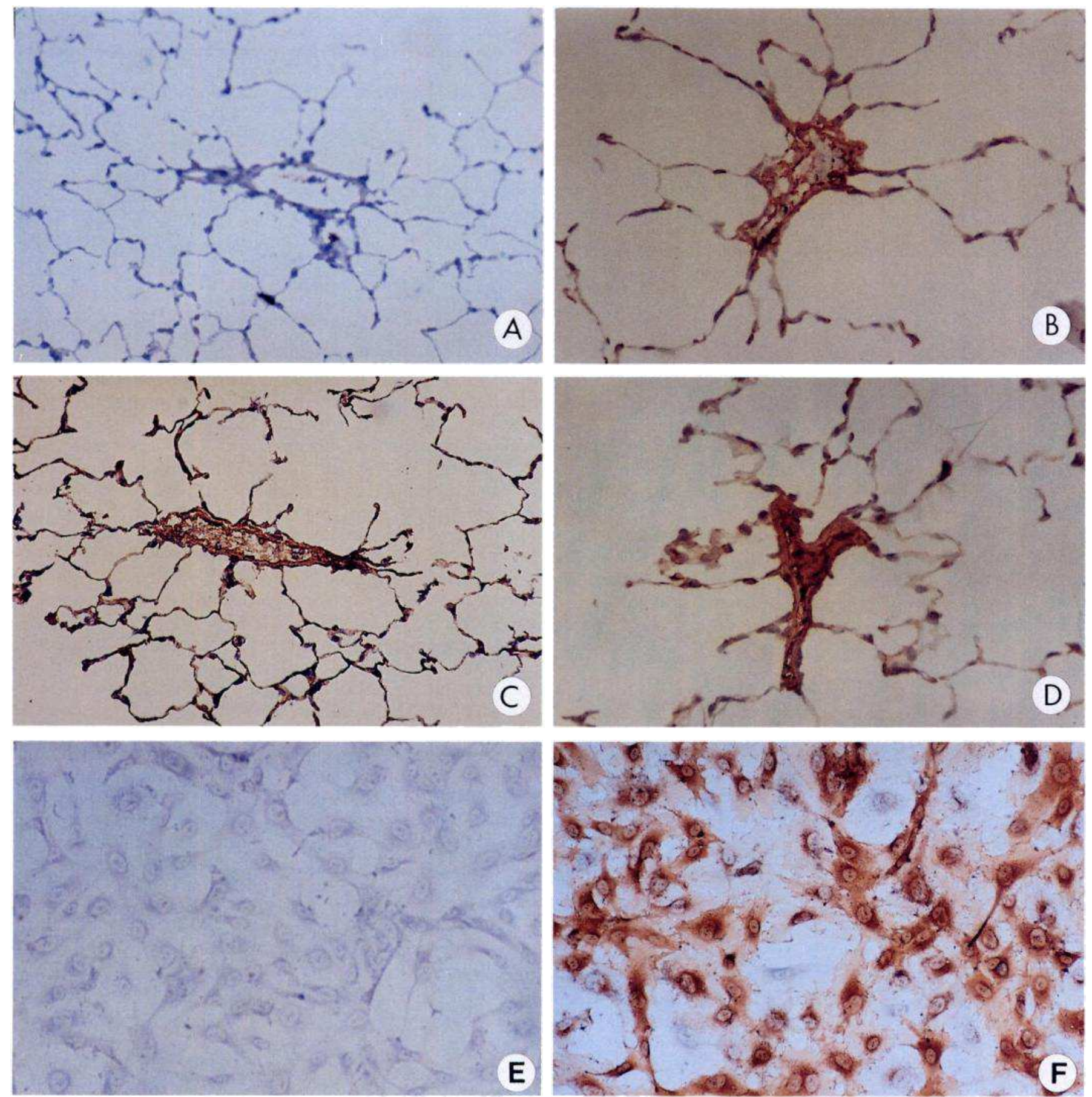

Figure 2. Pulmonary vascular expression of E-selectin. Panels $A-D$ represent immunoperoxidase staining of frozen sections of rat lung for E-selectin using a cross-reacting anti-human E-selectin monoclonal antibody. Normal lung $(A)$, lungs after intratracheal instillation of lipopolysaccharide $(B)$, murine IL-1 $(C)$, and murine TNF $\alpha(D)$. Panels $E$ and $F$ are rat pulmonary artery endothelial cells in culture stained for E-selectin: untreated endothelial cells $(E)$; endothelial cells treated for $4 \mathrm{~h}$ with TNF $\alpha(F) .(A-\mathrm{D}, \times 200: E, F, \times 400)(\mathrm{Mulligan}$, M. S., and Ward, P. A., unpublished results).

profiles involved in specific disease states, it may be possible to more precisely target therapy for use in long-term therapy. For example, if the combination of molecules that result in eosinophil infiltration were known, it might be possible to design a more effective therapy for asthma. Selective targeting of antiadhesion therapy to defined anatomic regions, such as delivery of a drug by inhalation or by instillation into an affected joint space, could also be a useful alternative. Critically important will be the identification organ or disease-specific CAMs. Endothelial proteins that target subsets of lymphocytes to the skin or certain subsets of lymph nodes $(80)$ have been recognized and raise the possibility that other such organ-specific homing receptors might also exist. 
We thank Dr. J. Pilewsky for his careful reading of this manuscript and valuable suggestions, Ms. Jacqueline Schaffer for the artwork, and Ms. Vanessa Mack for skillful preparation of the manuscript. We would also like to apologize to all the authors of the many excellent studies not referenced in this review because of space limitations. This work was supported by National Instifutes of Health grants HL49591 (S. M. A.), HL46311 (S. M. A.), HL31963 (P. A. W.), HL42550, AI23521, AI19031 (C. W. S.), and a grant from the Polly Annenberg Levee Charitable Trust (S. M. A.). S. M. A. is an Established Investigator of the American Heart Association.

\section{REFERENCES}

1. Albelda, S. M., and Buck, C. A. (1990) Integrins and other cell adhesion molecules. FASEB J. 4, 2868-2880

2. Pober, J. S., and Cotran, R. S. (1990) The role of endothelial cells in inflammation. Transplantation 50, 537-544

3. Butcher, E. C. (1991) Leukocyte-endothelial cell recognition: three (or more) steps to specificity and diversity. Cell 67, 1033-1036

4. von Andrian, U. H., Chambers, J. D., McEvoy, L. M., Bargatze, R. F., Arfors, K., and Butcher, E. C. (1991) Two-step model of leukocyteendothelial cell interaction in inflammation: distinct roles for LECAM-1 and the leukocyte $\beta_{2}$ integrins in vivo. Proc. Natl. Acad Sci. USA 88, 7538-7542

5. Smith, C. W. (1993) Endothelial adhesion molecules and their role in inflammation. Can. J. Physiol. Pharmacol. 71, 76-87

6. Harlan, J. M., Winn, R. K., Vedder, N. B., Doerschuk, C. M., and Rice, C. L. (1992) In vivo models of leukocyte adherence to endothelium. In Adhesion: Its Role in Inflammatory Disease (Harlan, J. M., and Lui, D. Y., eds) pp. 117-150, Freeman and Company, New York

7. Bevilacqua, M., and Nelson, R. M. (1993) Selectins. J. Clin. Invest. 91, 379-387

8. Lasky, L. A. (1992) Selectins: interpreters of cell-specific carbohydrate information during inflammation. Science 258, 964-969

9. Kishimoto, T. K., Jutila, M. A., Berg, E. L., and Butcher, E. C. (1989) Neutrophil Mac-1 and MEL-14 adhesion proteins inversely regulated by chemotactic factors. Science 245, 1238-1241

10. Baumhueter, S., Singer, M. S., Hanzel, W., Hemmerich, S., Renz, M., Rosen, S. D., and Lasky, L. A. (1993) Binding of L-selectin to the vascular sialomucin CD34. Science 262, 436438

11. Picker, L. J., Warnock, R. A., Burns, A. R., Doerschuk, C. M., Berg, E. L., and Butcher, E. C. (1991) The neutrophil selectin LECAM-1 presents carbohydrate ligands to the vascular selectins ELAM-1 and GMP140. Cell 66, 921-933

12. Abbassi, O., Kishimoto, T. K., McIntire, L. V., Anderson, D. C., and Smith, C. W. (1993) E-Selectin supports neutrophil rolling in vitro under conditions of flow. J. Clin. Invest. 92, 2719-2730

13. Sato, D., Chang, X-J., Barone, K. M., Vachino, G., White, H. M., Shaw, G., Veldman, G. M., Bean, K. M., Ahern, T. J., Furie, B., Cumming, D. A., and Larsen, G. R. (1993) Expression cloning of a functional glycoprotein ligand ligand for P-selectin. Cell 75, 1-20

14. von Andrian, U. H., Hansell, P., Chambers, J. D., Berger, E. M., Filho, I. T., Butcher, E. C., and Arfors, K.-E. (1992) L-selectin function is required for beta-2 integrin-mediated neutrophil adhesion at physiologic shear rates in vivo. Am.J. Physiol. 263, H1034-H1044

15. Anderson, D. C., Schmalsteig, F. C., Finegold, M. J., Hughes, B. J., Rothlein, R., Miller, L. J., Kohl, S., Fosi, M. F., Jacobs, R. L., Shearer, W. T., and Springer, T. A. (1985) The severe and moderate phenotypes of heritable Mac-1, LFA-1 deficiency: their quantitative definition and relation to leukocyte dysfunction and clinical features. J. Infect. Dis. 152 , 668-689

16. Wright, S. D., Lo, S. L., and Detmers, P. A. (1990) Specificity and regulation of CD18-dependent adhesions. In Loukogyte Adhesion Molecules. Structure, Function, and Regulation. (Springer, T. A., Anderson, D. C., Rosenthal, A. S., and Rothlein, R., eds) pp. 190-207, Springer-Verlag, New York

17. Lo, S. K., Van Seventer, G. A., Levin, S. M., and Wright, S. D. (1989) Two leukocyte receptors (CD11a/CD18) mediate transient adhesion to endothelium by binding to different ligands. J. Immunol. 143, 3325-3329

18. Figdor, C. G., Velde, A., and De Vries, J. E. (1989) The role of LFA-1 and related antigens in adhesion mediated functions of human monocytes. In Leukocyte Adhesion Molecules: Structure, Function, and Regulation. (Springer, T. A., Anderson, D. C., Rosenthal, A. S., and Rothlein, R., eds) pp. 159-169, Springer-Verlag, New York

19. Dransfield, I., Cabanas, C., Craig, A., and Hogg, N. (1992) Divalent cation regulation of the function of the leukocyte integrin LFA-1. J. Cell Biol. 116, 219-226
20. Luscinskas, F. W., Kiely, J., Ding, H., Obin, M. S., Herbert, C. A., Baker, J. B., and Gimbrone, M. A., Jr. (1992) In vitro inhibitory effect of IL-8 and other chemoattractants on neutrophil-endothelial adhesive interactions. J. Immunol. 149, 2163-2171

21. Zimmerman, G. A., Prescott, S. M., and McIntyre, T. M. (1992) Endothelial cell interactions with granulocytes: tethering and signaling molecules. Immunol. Today 13, 93-100

22. Rot, A. (1992) Endothelial cell binding of NAP-1/IL-8: role in neutrophil emigration. Immunol. Today 13, 291-294

23. Gimbrone, M. A., Jr., Obin, M. S., Brock, A. F., Luis, E. A., Hass, P. E., Hebert, C. A., Yip, Y. K., Leung, D. W., Lowe, D. G., Kohr, W. J., Darbonne, W. C., Bechtol, K. B., and Baker, J. B. (1989) Endothelial interleukin-8: a novel inhibitor of leukocyte-endothelial interactions. Science 246, 1601-1603

24. Huber, A. R., Kunkel, S. L., Todd, R. F., III, and Weiss, S. J. (1991) Regulation of transendothelial neutrophil migration by endogenous interleukin-8. Science 253, 1-4

25. Yan, H., Juhasz, I., Pilewski, J., Murphy, G. F., Herlyn, M., and Albelda, S. M. (1993) Human/severe combined immunodeficient mouse chimeras. An experimental in vivo model system to study the regulation of human endothelial cell-leukocyte adhesion molecules. J. Clin. Invest. 91, 986-996

26. Smith, C. W., Marlin, S. D., Rothlein, R., Toman, C., and Anderson, D. C. (1989) Cooperative interactions of LFA-1 and Mac-1 with intercellular adhesion molecule-1 in facilitating adherence and transendothelial migration of human neutrophils in vitro. J. Clin. Invest. 83, 2008-2017

27. Huang, A. J., and Silverstein, S. C. (1992) Mechanisms of neutrophil migration across endothelium. In Endothelial Cell Dysfunctions. (Simionescu, N., and Simionescu, M., eds) pp. 201-231, Plenum Press, New York

28. Rosengren, S., Olofsson, A. M., von Andrian, U. H., LundgrenAkerlund, E., and Arfors, K. (1991) Leukotriene B4-induced neutrophilmediated endothelial leakage in vitro and in vivo. J. Appl. Physiol. 71, $1322-1330$

29. Luscinskas, F. W., Cybulsky, M. I., Kiely, J., Peckins, C. S., Davis, V. M., and Gimbrone, M. A., Jr. (1991) Cytokine-activated human endothelial monolayers support enhance neutrophil transmigration via a mechanism involving both endothelial-leukocyte adhesion molecule-1 and intercellular adhesion molecule-1. J. Immunol. 146, 1617-1625

30. Muller, W. A., Weigl, S. A., Deng, X., and Phillips, D. M. (1993) PECAM-1 is required for transendothelial migration of leukocytes. $J$. Exp. Med. 178, 449-460

31. DeLisser, H. M., Newman, P. J., and Albelda, S. M. (1993) Platelet endothelial cell adhesion molecule (CD31). In Current Topics Microbiology and Immunology, Vol. 184, Leukocyte Homing and Differentiation (Dunon, D., Mackay, C. R., and Imhof, B. A., eds) pp. 37-45, Springer-Verlag, Heidelberg

32. Vaporciyan, A. A., DeLisser, H. M., Yan, H-C., Mendiguren, I. I., Thom, S. R., Jones, M. L., Ward, P. A., and Albelda, S. M. (1993) Involvement of platelet-endothelial cell adhesion molecule-1 in neutrophil recruitment in vivo. Science 262, 1580-1582

33. Tanaka, Y., Albelda, S. M., Horgan, K. J., Van Seventer, G. A., Shimizu, Y., Newman, W., Hallam, J., Newman, P. J., Buck, C. A., and Shaw, S. (1992) CD31 expressed on distinctive $T$ cell subsets is a preferential amplifier of $\beta_{1}$ integrin-mediated adhesion. J. Exp. Med. 176, 245-253

34. Huang, A. J., Manning, J. E., Bandak, T. M., Ratau, M. C., Hanser, K. R., and Silverstein, S. C. (1993) Endothelial cell cytosolic free calcium regulates neutrophil migration across monolayers of endothelial cells. J. Cell Biol. 120, 1371-1380

35. Anderson, D. C., Miller, L. J., Schmalstieg, F. C., Rothlein, R., and Springer, T. A. (1986) Contributions of the Mac-1 glycoprotein family to adherence-dependent granulocyte functions: structure-function assessments employing subunit-specific monoclonal antibodies. J. Immunol. 137, 15-27

36. Buttrum, S. M., Hatton, R., and Nash, G. B. (1993) Selectin-mediated rolling of neutrophils on immobilized platelets. Blood 82, 1165-1174

37. Watson, S. R., Fennie, C., and Lasky, L. A. (1991) Neutrophil influx into an inflammatory site inhibited by a soluble homing receptor-IgG chimaera. Nature (London) 349, 164-166

38. Mulligan, M. S., Watson, S. R., Fennie, C., and Ward, P. A. (1993) Protective effects of selectin chimeras in neutrophil-mediated lung injury. J. Immunol. 151, 6410-6417

39. Mulligan, M. S., Paulson, J. C., De Frees, S., Zheng, Z-L., Lowe, J. B., and Ward, P. A. (1993) Protective effects of oligosaccharides in P. selectin-dependent lung injury. Nature (London) 364, 149-151

40. Geng, J-G., Moore, K. L., Johnson, A. E., and McEver, R. P. (1991) Neutrophil recognition requires a $\mathrm{CA}^{2+}$-induced conformational change in the lectin domain of GMP-140. J. Biol Chem. 266, 22313-22318

41. Ross, L., Hassman, F., and Malony, L. (1992) Inhibition of molt-4-endothelial adherence by synthetic peptides from the sequence of ICAM-1. J. Biol. Chem. 267, 8537-8543

42. Etzioni, A., Frydman, M., Pollack, S., Avidor, I., Phillipe, M. L., Paul- 
son, J. C., and Gershoni-Baruch, R. (1993) Brief report: recurrent severe infections caused by a novel leukocyte adhesion deficiency. $N$. Engl. J. Med. 327, 1789-1792

43. von Andrian, U. H., Berger, E. M., Ramezani, L., Chambers, J. D., Ochs, H. D., Harlan, J. M., Paulson, J. C., Etzioni, A., and Arfors, K. (1993) In vivo behavior of neutrophils from two patients with distinct inherited leukocyte adhesion deficiency syndromes. J. Clin. Invest. 91, 2893-2897

44. Wilson, R. W., Ballantyne, C. M., Smith, C. W., Montgomery, C., Bradley, A, O'Brien, W. E., and Beaudet, A. L. (1993) Gene targeting yields a CD18-mutant mouse for study of inflammation. $J$. Immunol. 151, 1571-1578

45. Wolitzky, B., Kwee, L., Terry, R., Kontgen, F., Stewart, C., Rumberger, J. M., Burns, D. K., and Labow, M. A. (1994) Targeted disruption of the murine E-selectin and VCAM-1 genes. J. Cell. Biochem. Suppl. 18A, 300

46. Sligh, J. E., Jr., Ballantyne, C. M., Rich, S. S., Hawkins, H. K., Smith, C. W., Bradley, A., and Beaudet, A. L. (1993) Inflammatory and immune responses are impaired in ICAM-1 deficient mice. Proc. Natl. Acad. Sci. USA 90, 8529-8533

47. Mayadas, T. N., Johnson, R. C., Rayburn, H., Hynes, R. O., and Wagner, D. D. (1993) Leukocyte rolling and extravasation are severely compromised in P-selectin-deficient mice. Cell 74, 541-554

48. Mulligan, M. S., Varani, J., Dame, M. K., Lane, C. L., Smith, C. W., Anderson, D. C., and Ward, P. A. (1991) Role of endothelial-leukocyte adhesion molecule 1 (ELAM-1) in neutrophil-mediated lung injury in rats. J. Clin. Invest. 88, 1396-1406

49. Jutila, M. A., Rott, L., Berg, E. L., and Butcher, E. C. (1989) Function and regulation of the neutrophil MEL-14 antigen in vivo: comparison with LFA-1 and MAC-1. J. Immunol. 143, 3318-3324

50. Ley, K., Gaehtgens, P., Kennie, C., Singer, M. S, Lasky, L. A., and Rosen, S. D. (1991) Lectin-like cell adhesion molecule 1 mediates leukocyte rolling in mesenteric venules in vivo. Blood 77, 2553-2555

51. Gundel, R. H., Wegner, C. D., Torcellini, C. A., Clarke, C. C., Haynes, N., Rothlein, R., Smith, C. W., and Letts, L. G. (1991) Endothelial leukocyte adhesion molecule-1 mediates antigen-induced acute airway inflammation and late-phase airway obstruction in monkeys. J. Clin. Invest. 88, 1407-1411

52. Yan, H-C., DeLisser, H. M., Pilewski, J. M., Barone, K. M., Szklut, P. J., Chang, X-J, Ahern, T. J., Langer-Safer, P., and Albelda, S. M. (1994) Leukocyte recruitment into human skin transplanted onto severe combined immunodeficient mice induced by tumor necrosis factor $\alpha$ is dependent on E-selectin. J. Immunol. 152, 3063-3063

53. Mulligan, M. S., Polley, M. J., Bayer, R. J., Nunn, M. F., Paulson, J. C., and Ward, P. A. (1992) Neutrophil-dependent acute lung injury-requirement for P-selectin (GMP-140). J. Clin. Invest. 90, 1600-1607

54. Weyrich, A. S., Ma, X-L, Lefer, D. J., Albertine, K. H., and Lefer, A. M. (1993) In vivo neutralization of P-selectin protects feline heart and endothelium in myocardial ischemia and reperfusion injury. J. Clin. Invest. 91, 2620-2629

55. Winn, R. K., Liggitt, D., Vedder, N. B., Paulson, J. C., and Harlan, J. M. (1993) Anti-P-selectin monoclonal antibody attenuates reperfusion injury to the rabbit ear. J. Clin. Invest. 92, 2042-2047

56. Doerchuk, C. M., Winn, R. K., Coxson, H. O., and Harlan, J. M. (1990) CD18-dependent and -independent mechanisms of neutrophil emigration in the pulmonary and systemic microcirculation of rabbits. J. Immunol. 144, 2327-2333

57. Winn, R. K., and Harlan, J. M. (1993) CD18-independent neutrophil and mononuclear leukocyte emigration into the peritoneum of rabbits. J. Clin. Invest. 92, 1168-1173

58. Mulligan, M. D., Varani, J., Warren, J. S., Till, G. O., Smith, C. W., Anderson, D. C., and Todd, R. F., III (1992) Roles of $\beta_{2}$ integrins of rat neutrophils in complement- and oxygen radical-mediated acute inflammatory injury. J. Immunol. 148, 1847-1857

59. Mulligan, M. S., Warren, J. S., Smith, C. W., Anderson, D. C., Yeh, C. G., Rudolph, A. R., and Ward, P. A. (1992) Lung injury after deposition of IgA immune complexes. J. Immunol. 148, 3086-3092

60. Mulligan, M. S., Johnson, K. J., Todd, R. F., III, Issekutz, T. B. Miyasaka, M., Tamatani, T., Smith, C. W., Anderson, D. C., and Ward, P. A. (1993) Requirements for leukocyte adhesion molecules in nephrotoxic nephritis. J. Clin. Invest. 91, 577-587

61. Mulligan, M. S., Smith, C. W., Anderson, D. C., Todd, R. F., III,
Miyasaka, M., Tamatani, T., Issekutz, T. B., and Ward, P. A. (1993) Role of leukocyte adhesion molecules in complement-induced lung injury. J. Immunol. 150, 2401-2406

62. Mulligan, M. S., Wilson, G. P., Todd, R. F., Smith, C. W., Anderson, D. C., Varani, J., Issekutz, T. B., Myasaka, M., Tamatani, T., Rusche, J. R., Vaporciyan, A. A., and Ward, P. A. (1993) Role of $\beta_{1}, \beta_{2}$ integrins and ICAM-1 in lung injury after deposition of IgG and IgA immune complexes. J. Immunol. 150, 2407-2417

63. Fischer, A., Griscelli, C., Blanche, S., LeDeist, F., Veber, F., Lopez, M., DeLaage, M., Olive, D., Mawas, C., and Janossy, G. (1986) Prevention of graft failure by an anti-HLA-1 monoclonal antibody in HLAmismatched bone marrow transplantation. Lancet 2, 1058-1061

64. Haug, C. E., Colvin, R. B., Delmonico, F. L., Atuchincloss, H., Jr., Rolkoff-Rubin, N., Preffer, F. I., Rothlein, R., Norris, S., Scharschmidt, L., and Cosimi, A. B. (1993) A phase I trial of immunosuppression with anti-ICAM-1 (CD54) mAb in renal allograft recipients. Transplantation 55, 766-773

65. Gamble, J. R., Skinner, M. P., Berndt, M. C., and Vadas, M. A. (1990) Prevention of activated neutrophil adhesion to endothelium by soluble adhesion protein GMP140. Science 249, 414-417

66. Lobb, R. R., Chi-Rosso, G., Leone, D. R., Rosa, M. D., Bixler, S., Newman, B. M., Luhowskij, S., Benjamin, C. D., Gougas, I. G., Goelz, S. E., Hession, C., and Chow, E. P. (1991) Expression and functional characterization of a soluble form of endothelial-leukocyte adhesion molecule 1. J. Immunol. 147, 124-129

67. Fecondo, J. V., Kent, S. B. H., and Boyd, A. (1991) Inhibition of intercellular adhesion molecule 1-dependent biological activities by a synthetic peptide analog. Proc. Natl. Acad. Sci. USA 88, 2879-2882

68. DeLisser, H. M., Yan, H-C., Newman, P. J., Muller, W. A., Buck, C. A., and Albelda, S. M. (1993) Platelet/endothelial cell adhesion molecule-1 (CD31)-mediated cellular aggregation involves cell surface glycosaminoglycans. J. Biol. Chem. 268, 16037-16046

69. Nelson, R. M., Dolich, S., Aruffo, A., Cecconi, O., and Bevilacqua, M. P. (1993) Higher-affinity oligosaccharide ligands for E-selectin. J. Clin. Invest. 91, 1157-1166

70. Bennett, C. F., Condon, T. P., Grimm, S., Chan, H., and Chiang, M-Y. (1994) Inhibition of endothelial cell adhesion molecule expression with antisense oligonucleotides. $J$. Immunol. In press

71. Bennett, C. F. (1994) Regulation of leukocyte-endothelial cell adhesion molecule expression with synbtheitic oligonucleotides. J. Cell. Biochem. Suppl. 18A, 262

72. Chopra, J., and Webster, R. O. (1988) $\mathrm{PGE}_{2}$ inhibits neutrophil adherence and neutrophil-mediated injury to cultured endothelial cells. $\mathbf{A m}$. Rev. Resp. Dis. 138, 915-920

73. Colgan, S. P., Serhan, C. N., Parkos, C. A., Delp-Archer, C., and Madara, J. L. (1993) Lipoxin A modulates transmigration of human neutrophils across intestinal epithelial monolayers. J. Clin. Invest. 92, 75-82

74. Kubes, P., Suzuki, M., and Granger, D. N. (1991) Nitric oxide: an endogenous modulator of leukocyte adhesion. Proc. Natl. Acad. Sci. USA 88, 4651-4655

75. Cronstein, B. N., Levin, R. I., Philips, M., Hirschhorn, R., Abramson, S. B., and Weissmann, G. (1992) Neutrophil adherence to endothelium is enhanced via adenosine $A_{1}$ receptors and inhibited via adenosine $A_{2}$ receptors. J. Immunol. 148, 2201-2206

76. Booth, S. A., Moody, C. E., Dahl, M. V., Herron, M. J., and Nelson, R. D. (1992) Dapsone suppresses integrin-mediated neutrophil adherence function. $J$. Invest. Dermatol. 98, 135-140

77. Burch, R. M., Weitzberg, M., Blok, N., Muhlhauser, R., Martin, D., Farmer, S. G., Bator, J. M., Connor, J. R., Ko, C., Kuhn, W., McMillan, B. A., Raynor, M., Shearer, B. G., Tiffany, C., and Wilkins, D. E. (1991) N-Fluorenyl-9-methoxycarbonyl amino acids, a class of antiinflammatory agents with a different mechanism of action. Proc. Natl. Acad. Sci. USA 88, 355-259

78. Burch, R. M., Noronha-Blob, L., Bator, J. M., Lowe, V. C., and Sullivan, J. P. (1993) Mice treated with a leumedin or antibody to Mac-1 to inhibit leukocyte sequestration survive endotoxin challenge. $\mathrm{J}$. Immunol. 150, 3397-3403

79. Kubes, P. (1993) Polymorphonuclear leukocyte-endothelium interactions: a role for pro-inflammatory and anti-inflammatory molecules. Can. J. Physiol. Pharmacol. 71, 88-97

80. Picker, L. J., and Butcher, E. C. (1992) Physiological and molecular mechanisms of lymphocyte homing. Annu. Rev. Immunol. 10, 561-583 